\title{
Influence of Melt-Pouring Temperature and Composition of Primary Coating of Shell Mold on Tensile Strength and Creep Resistance of Ni-Based Superalloy
}

\author{
Łukasz Rakoczy, Małgorzata Grudzień, and Rafał Cygan
}

\author{
(Submitted October 12, 2018; in revised form November 18, 2018; published online January 4, 2019)
}

\begin{abstract}
Eight investment castings of Inconel $713 \mathrm{C}$ superalloy were fabricated, varying in the melt-pouring temperature, from 1400 to $1520{ }^{\circ} \mathrm{C}$, and $\mathrm{CoAl}_{2} \mathrm{O}_{4}$ inoculant content, 0 or 5 wt.\%, in the primary coat. Their influence on grain size on tensile and creep properties was investigated. The best combination of yield stress $(815 \mathrm{MPa})$ and elongation $\left(A_{4}=\mathbf{7 . 6 5 \%}\right)$ at ambient temperature was obtained in surface-modified castings poured from $1520^{\circ} \mathrm{C}$. The longest time to rupture was for the unmodified castings $(76.8 \mathrm{~h})$ poured from $1520{ }^{\circ} \mathrm{C}$, while for the modified variant, the time to rupture was lower around, $7.4 \mathrm{~h}$, which was still a satisfactory value. During tensile testing, microcracks were formed in large eutectic $\gamma^{\prime}$, carbides and borides, due to the accumulation of stress at interfaces with the matrix. During creep, $N$-type rafting of $\gamma^{\prime}$ precipitates and phase transformation $\mathrm{MC}+\gamma \rightarrow \gamma^{\prime}+\mathrm{M}_{23} \mathrm{C}_{6}$ took place.
\end{abstract}

Keywords aviation, casting, creep, IN713C, jet engine

\section{Introduction}

Precipitation-strengthened nickel-based superalloys are widely used in the manufacturing of turbine blades and vanes, which operate in hot sections, both in turbochargers of combustion engines and turbofan jet engines (Ref 1,2). One of the most important representatives of this group is Inconel 713C. This alloy is also extensively used in the automotive, power and oil and gas industries due to a unique combination of strength at operating temperature and excellent hot corrosion resistance. The very good castability, low-cycle fatigue resistance (LCF) and microstructural stability determine the wide use of the Inconel 713C for low-pressure turbine (LPT) guide vanes in GP7200 engines (Ref 3-6). Usually, superalloys are heat-treated (solution + aging); however, Inconel $713 \mathrm{C}$ achieves sufficiently high properties in the as-cast condition, and so increase in mechanical properties is by optimization of investment casting parameters and composition of the shell mold (Ref 7). Major features of investment castings are macrostructural coarseness and non-uniformity of grain size,

This article is an invited submission to JMEP selected from presentations at the 73rd World Foundry Congress and has been expanded from the original presentation. 73WFC was held in Krakow, Poland, September 23-27, 2018, and was organized by the World Foundry Organization and Polish Foundrymen's Association.

Lukasz Rakoczy, Faculty of Metals Engineering and Industrial Computer Science, AGH University of Science and Technology, av. Mickiewicza 30, 30-059 Kraków, Poland; Malgorzata Grudzień, Foundry Research Institute, ul. Zakopianska 73, 30-418 Kraków, Poland; and Rafal Cygan, Consolidated Precision Products, Investment Casting Division, ul. Hetmanska 120, 35-078 Rzeszow, Poland. Contact e-mail: lrakoczy@agh.edu.pl. which may reduce the fatigue life and reliability of turbine vanes in the intermediate temperature range. The microstructure improvement of cast superalloys may be obtained by more uniform equiaxed grain size (Ref 8-10). Desired grain size can be achieved by selection of melt-pouring temperature, preheat of ceramic shell mold, and/or introduction of an inoculant into the primary coat (Ref 11,12 ). Grain refinement through the addition of inoculants is an important way to increase the strength of cast polycrystalline superalloys. At a relatively low temperature, the strength of the grain boundary is higher than that of the grain interior and so increasing the area of grain boundaries can increase the strength of superalloys. However, with the increase in operating temperature, the strength of grain boundary decreases more quickly than the grain interior strength. Increasing the grain boundary area can, therefore, lead to a significant reduction in strength. Grain refinement by the addition of inoculants has several benefits, namely a substantially easy operation, no change in production equipment and a very good refining effect (Ref 13, 14). It has been reported (Ref 13, 15-18) that inoculants have a favorable influence on grain refinement and thus low-temperature mechanical properties. The main aim of this research was to determine the influence of the melt-pouring temperature and the $\mathrm{CoAl}_{2} \mathrm{O}_{4}$ inoculant in the prime coat of the shell mold on the structure and mechanical properties of IN713C superalloy castings.

\section{Material and Experimental Procedure}

Ni-based superalloy Inconel $713 \mathrm{C}$ was used as the casting and the gating system. Result of chemical composition analysis obtained by optical emission spectroscopy is shown in Table 1 .

The eight shell molds were fabricated in the Investment Casting Division of Consolidated Precision Products Corp. Each of the disposable wax assemblies consisted of a "carrot"type shape specimens with dimensions: bottom diameter $23 \mathrm{~mm}$, upper diameter $12 \mathrm{~mm}$ and height $90 \mathrm{~mm}$. Four vents 
Table 1 Chemical composition of Ni-based superalloy Inconel 713C

\begin{tabular}{lccccccccc}
\hline Element & $\mathbf{C r}$ & Al & Mo & Nb & Ti & C & Zr & B & Ni \\
\hline wt.\% & 14.14 & 5.78 & 4.38 & 2.16 & 0.87 & 0.10 & 0.07 & 0.012 & Bal. \\
\hline
\end{tabular}

were prepared in order to stabilize and strengthen the wax models and also for better wax melting. The wax patterns were injection molded, and then, the ceramic monolithic mold was built up around these patterns by a series of dip coatings ( 8 layers). Alumina grit was used as the primary stucco. One of the prepared shell molds is shown in Fig. 1. Two prime coats were produced for the casting:

(a) Shell molds no. 1, 3, 5, 7: zircon filler and colloidal silica binder,

(b) Shell molds no. 2, 4, 6, 8: zircon filler and colloidal silica binder plus $5 \mathrm{wt} \%$ of $\mathrm{CoAl}_{2} \mathrm{O}_{4}$ inoculant.

The wax patterns were removed from the shell molds in boilerclave and then covered with alumina silicate Fiberfrax ${ }^{\circledR}$ insulation. All molds were then fired to increase the strength and remove the wax residue. Directly before melt-pouring, the molds were placed in a heating chamber preheated to $1000{ }^{\circ} \mathrm{C}$ for $100 \mathrm{~min}$. The temperature was controlled by $\mathrm{Pt} / \mathrm{Pt}-\mathrm{Rh}$ thermocouples. The raw ingots were melted in a zirconia crucible placed in a vacuum induction furnace. The Inconel 713C superalloy was inductively melted in a vacuum of $2.9 \times 10^{-3} \mathrm{~Pa}$. The liquid superalloy was poured into molds at four different temperatures: $1400,1450,1480$ and $1520{ }^{\circ} \mathrm{C}$. A total of 40 specimens were machined for microstructural and mechanical properties investigations. Those for macroscopic and microscopic examinations were mounted in resin, metallographically prepared (grinding and polishing) and finally chemically etched in $50 \mathrm{~mL}$ lactic acid, $30 \mathrm{~mL}$ nitric acid, $2 \mathrm{~mL}$ hydrofluoric acid (macro) and electrochemically (micro) in $10 \% \mathrm{CrO}_{3}$. Tensile tests were carried out at ambient temperature according to ASTM E8M-13a standard (Ref 19) using INSTRON 3382 tester, and yield strength and elongation $A_{4}$ were determined. The geometry of the sample is presented in Fig. 2.

Creep tests were performed on a Walter + Bai AG LFMZ30 machine in accordance with the requirements of ASTM E139-11 standard (Ref 20). The samples were preheated to $982{ }^{\circ} \mathrm{C}$, annealed for $60 \mathrm{~min}$, and then loaded with an axial force, which produced in their cross sections an initial tensile stress of $151.8 \mathrm{MPa}$. Two specimens were prepared for creep and two for the tensile testing (for each variant presented in Table 2), and finally, average values were calculated. The solidus temperature of Inconel $713 \mathrm{C}$ is $1263{ }^{\circ} \mathrm{C}$ (Ref 11 ), so creep testing was at a high homologous temperature, 0.82 .

\section{Results and Discussion}

\subsection{Microstructure of Castings}

The microstructures of castings did not reveal casting defects like cracks, porosity and misruns (Fig. 3). The increase in melt-pouring temperature induced a decrease in cooling rate which led to grain growth. The microstructure showed that

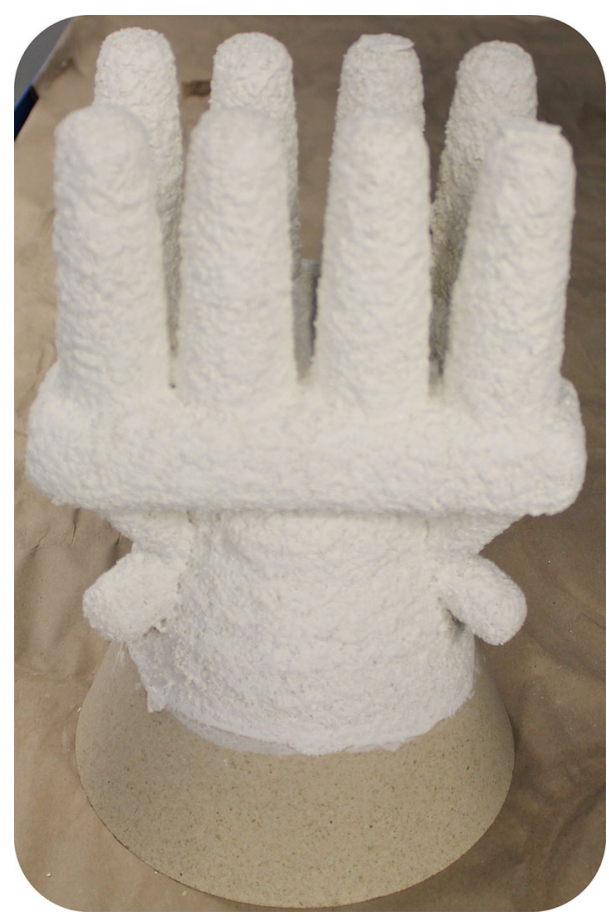

Fig. 1 Shell mold fabricated through the "dip and stucco" technique

cobalt aluminate $\left(\mathrm{CoAl}_{2} \mathrm{O}_{4}\right)$ was an effective modifier for Inconel $713 \mathrm{C}$ in the whole range of melt-pouring temperatures, especially at 1450 and $1520{ }^{\circ} \mathrm{C}$. Differential thermal analysis of IN713C indicated that the creation of the first $\gamma$ primary dendrites started at $1342{ }^{\circ} \mathrm{C}$ (liquidus) (Ref 11). The solidification finished at $1263{ }^{\circ} \mathrm{C}$, and so liquidus-solidus range is relatively wide, $79^{\circ} \mathrm{C}$. Table 1 indicates that IN713C consists of highly reactive alloying elements like chromium, aluminum, as well as titanium, characterized by high oxygen affinity. During the contact of the primary coat with the liquid alloy, cobalt aluminate was reduced and metallic cobalt was created in accordance with the reactions (Ref 13):

$$
\begin{aligned}
& \mathrm{CoAl}_{2} \mathrm{O}_{4}+2 / 3 \mathrm{Cr} \rightarrow 1 / 3 \mathrm{Cr}_{2} \mathrm{O}_{3}+\mathrm{Co}+\mathrm{Al}_{2} \mathrm{O}_{3} ; \\
& \mathrm{CoAl}_{2} \mathrm{O}_{4}+2 / 3 \mathrm{Al} \rightarrow 3 / 4 \mathrm{Al}_{2} \mathrm{O}_{3}+\mathrm{Co} \\
& \mathrm{CoAl}_{2} \mathrm{O}_{4}+1 / 2 \mathrm{Ti} \rightarrow 1 / 2 \mathrm{TiO}_{2}+\mathrm{Co}+\mathrm{Al}_{2} \mathrm{O}_{3} ;
\end{aligned}
$$

Cobalt from the inoculant was superseded by $\mathrm{Al}, \mathrm{Cr}$ and $\mathrm{Ti}$, and then, Co fine particles were formed on the internal surfaces of shell molds. Above $450{ }^{\circ} \mathrm{C}$, cobalt and $\gamma(\mathrm{Ni})$ phase have the same crystallographic structure (face-centered cubic). The lattice constants are $a_{\mathrm{Co}}=3.5480 \AA$ and $a_{\mathrm{Ni}}=3.5805 \AA$, respectively, which gives a low lattice misfit (Ref 21,22$)$. In accordance with the equation $f=\frac{a_{\mathrm{Ni}}-a_{\mathrm{Co}}}{a_{\mathrm{Co}}} \times 100 \%$, misfit is only 


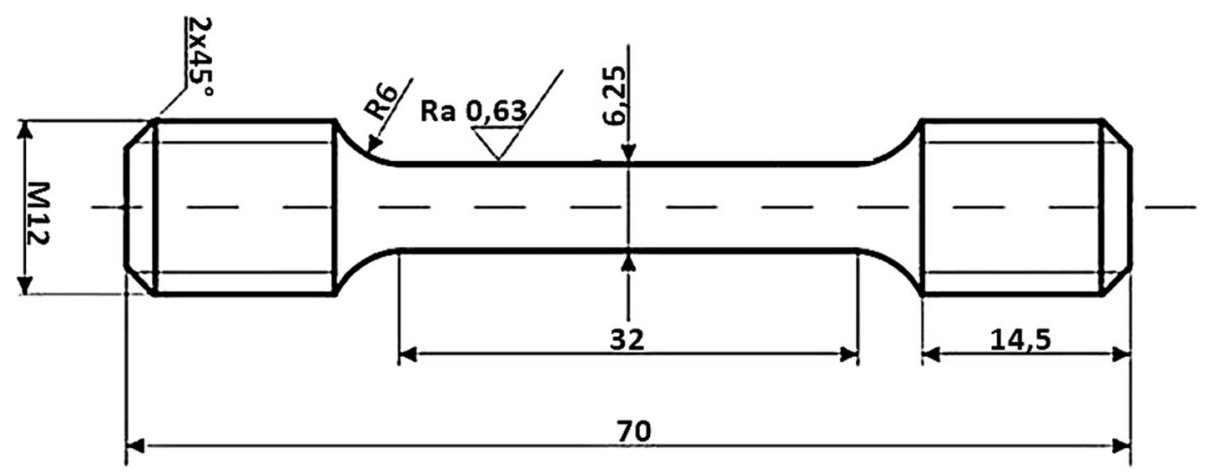

Fig. 2 Geometry of specimen for tensile and creep tests

Table 2 Designation of shell molds

\begin{tabular}{lcc}
\hline $\begin{array}{l}\text { Shell } \\
\text { mold, No. }\end{array}$ & $\begin{array}{c}\text { Content of inoculant in prime } \\
\text { coat, wt. } \%\end{array}$ & $\begin{array}{c}\text { Melt-pouring } \\
\text { temperature, }{ }^{\circ} \mathbf{C}\end{array}$ \\
\hline 1 & 0 & 1400 \\
2 & 5 & 1400 \\
3 & 0 & 1450 \\
4 & 5 & 1450 \\
5 & 0 & 1480 \\
6 & 5 & 1480 \\
7 & 0 & 1520 \\
8 & 5 & 1520 \\
\hline
\end{tabular}

\section{Unmodified}

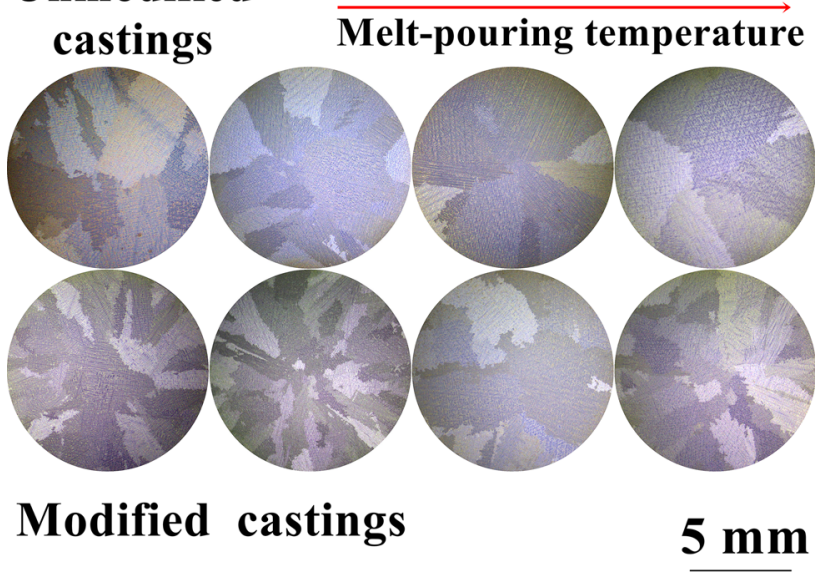

Fig. 3 Macrostructure of castings

$0.9 \%$ and Co can act as a good nucleation substrate. The heterogeneous nucleation rate of the cast surface was increased. The modification gave an exothermic reaction during pouring, which prevented the formation of a chill zone structure. It is also important to mention that some other variables have also an influence on the microstructure of superalloys, and consequently on mechanical properties. An increase in the meltpouring temperature influences strongly the reactivity of the molten alloy with the crucible and filter. Alloys poured from higher temperatures have also a higher concentration of vacancies, which is important for mechanical properties at high homologous temperatures (Ref 1, 2).
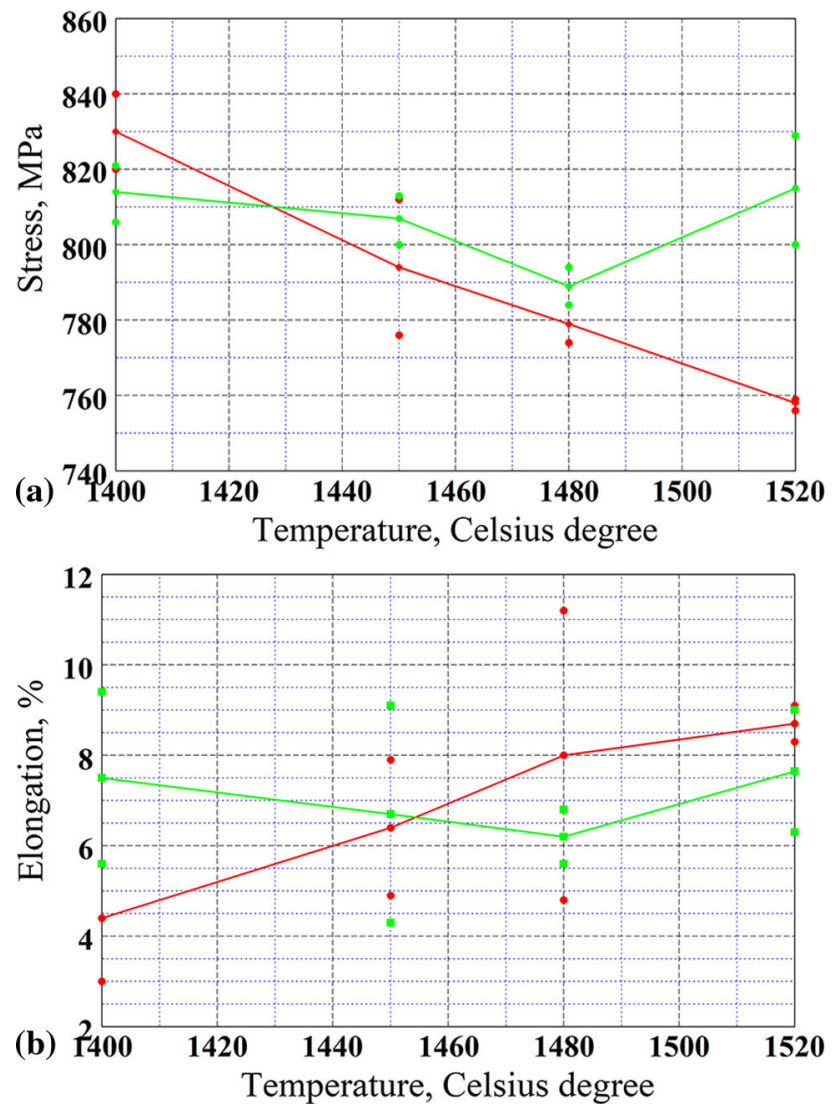

Fig. 4 Influence of pouring temperature on: (a) yield strength; (b) elongation $A_{4}$

\subsection{Tensile Tests Results and Changes of Microstructure}

The results of the tensile tests are shown in Fig. 4. The averaged values calculated are joined by the green line for the modified samples and by the red line for the unmodified. According to the AMS 5391 standard (Ref 23), Inconel 713C castings should be characterized by the following properties: yield strength $689.5 \mathrm{MPa}(100 \mathrm{psi})$ and elongation $A_{4}$ min. $3 \%$. Yield stress in all samples significantly exceeded the required minimum (Fig. 4a). With the exception of the melt-pouring temperature of $1400{ }^{\circ} \mathrm{C}$, higher average values were obtained for the modified samples. The difference between the highest $(830 \mathrm{MPa})$ and the lowest mean value was around $76 \mathrm{MPa}$. For unmodified samples, yield stress decreased as the casting 
temperature increased. The elongation $A_{4}$ is presented in Fig. 4(b). Relatively low values were measured in unmodified samples poured from $1400{ }^{\circ} \mathrm{C}$. The highest $A_{4}$ values for both modified and unmodified samples were obtained for $1520{ }^{\circ} \mathrm{C}$ pouring temperature. The results of single measurements for melt-pouring temperatures of 1450 and $1480{ }^{\circ} \mathrm{C}$ were close to $4 \%$ minimum.

Macrostructures of cross-sectioned specimens after the tensile test are shown in Fig. 5. The complex character of cracking indicated structural heterogeneity of the castings. Conventionally, higher yield strength was associated with finer grain size. High strength also results from a high volume fraction of the $\gamma^{\prime}$ precipitates, narrow matrix channels and the solid solution strengthening effect in both matrix and $\gamma^{\prime}$ phases. The total content of $\gamma^{\prime}$ formers exceeded $6.6 \mathrm{wt} . \%$, which is a relatively high value in comparison with other equiaxed superalloys widely used in aircraft engines (Ref 24). Plastic deformation of the superalloys occurs through dislocations slip in the matrix channels. A high volume fraction of the $\gamma^{\prime}$ phase and the substantial local grain-boundary curvature in castings effectively block their movement.

The microstructural changes, the location of EDS points and results of the analysis are presented in Fig. 6 and Table 3. Numerous cracks have been observed inside many large precipitates. The results of analysis no. 1 and 2 revealed the increased concentration of $\mathrm{Ni}$ and $\mathrm{Al}$ which confirmed the presence of eutectic $\gamma^{\prime}$. Precipitates strongly enriched in $\mathrm{Nb}, \mathrm{Ti}$ and Mo were MC-type carbides (points 3 and 4), while the precipitates with a total concentration of around 75 at. $\%$ of Mo and $\mathrm{Cr}$ were $\mathrm{M}_{3} \mathrm{~B}_{2}$ borides (points 5 and 6). The uncracked precipitates along interdendritic spaces were $\mathrm{Ni}_{7} \mathrm{Zr}_{2}$ intermetallic compounds formed from the residual liquid phase through the eutectic transformation. The deformation of $\gamma^{\prime}$ phase takes place by slip on systems $\{111\}<110>$. The dislocation in $\gamma^{\prime}$ phase has a length of Burger vector $\mathrm{a} \sqrt{2}$, which is twice as long as in $\gamma$. Dislocation slip in the $\gamma^{\prime}$ by one length of the Burgers vector disturbs the lattice order. This leads to the formation of a high energy defect, so dislocation movement in the $\gamma^{\prime}$ is more difficult (Ref 25). The microstructural observations and tensile tests results indicated that the deformation of IN713C was dominated by the type of primary precipitates and dislocation movement in the matrix. Due to the high stiffness of eutectic $\gamma^{\prime}$ phase, carbides and borides, accumulation of created dislocations occurred in the $\gamma$ matrix and interfaces. Microcracks of large precipitates confirmed the stress concentration along interfaces with the matrix. In the Ni-based superalloys, interfaces $\gamma / \mathrm{MC}$-type carbides and $\gamma /$ eutectic $\gamma^{\prime}$ are areas of increased stress concentration (Ref 26, 27).

\subsection{Creep Tests Results and Changes of Microstructure}

The AMS5391 (Ref 23) standard indicates that with the assumed test parameters the time to rupture should be at least $30 \mathrm{~h}$. The creep properties of castings tested at $982{ }^{\circ} \mathrm{C}$ and $151.8 \mathrm{MPa}$ as a function of melt-pouring temperature are presented in Fig. 7(a) and (b). The creep life was improved with increasing pouring temperature, and in addition, the mean time to rupture for each melt-pouring temperature was higher for the unmodified samples (Fig. 7a). The mean time to rupture for unmodified and modified castings poured from $1400{ }^{\circ} \mathrm{C}$ was 48.1 and $46.0 \mathrm{~h}$, respectively. Increasing the pouring temperature by $120{ }^{\circ} \mathrm{C}$ contributed to the increase in these values by more than $50 \%$, namely to $76.8 \mathrm{~h}$ and $69.4 \mathrm{~h}$. The minimum value defined by the standard has been exceeded twice. The effect of cobalt aluminate was most pronounced at $1480{ }^{\circ} \mathrm{C}$, with a difference in mean time to rupture over $11 \mathrm{~h}$. Depending on the temperature and the load, three creep ranges were observed. At high temperature and low stress $\left(982{ }^{\circ} \mathrm{C} /\right.$ 151.8 $\mathrm{MPa}$ ), curves showed a short primary stage and steady state characterized by a plateau and pronounced strain at the tertiary stage.

The steady-state creep rate decreased with an increase in the melt-pouring temperature, both for the unmodified and the modified castings (Fig. 7b). The highest creep rate for the modified variant was $0.035 \% / \mathrm{h}\left(1450{ }^{\circ} \mathrm{C}\right)$, while the lowest $0.0245 \% / \mathrm{h}\left(1520{ }^{\circ} \mathrm{C}\right)$. In the unmodified castings, the difference between the highest $0.0306 \% / \mathrm{h}\left(1400{ }^{\circ} \mathrm{C}\right)$ and the lowest creep rate $\left(1520^{\circ} \mathrm{C}\right)$ was $0.0093 \% / \mathrm{h}$. The creep rate of modified samples was higher for each melt-pouring temperature, although the value calculated for the $1520{ }^{\circ} \mathrm{C}$ variant was the second lowest in the entire study. The comparison of creep curves which represents variants with the highest (modified at $1450{ }^{\circ} \mathrm{C}$ ) and the lowest (unmodified at $1520^{\circ} \mathrm{C}$ ) steady-state creep rate is presented in Fig. 7(c). Generally, the creep mechanisms can be divided into dependent and independent of the grain size ( $\operatorname{Ref} 1,8,28)$. In both cases, the creep rate is related to the diffusion rate. Creep diffusion via formation and disappearance of vacancies at the boundaries depends strongly on grain size, but dislocation creep which occurs inside the grains is independent of their size. Under constant stress and temperature, as the grain size increases, the contribution of
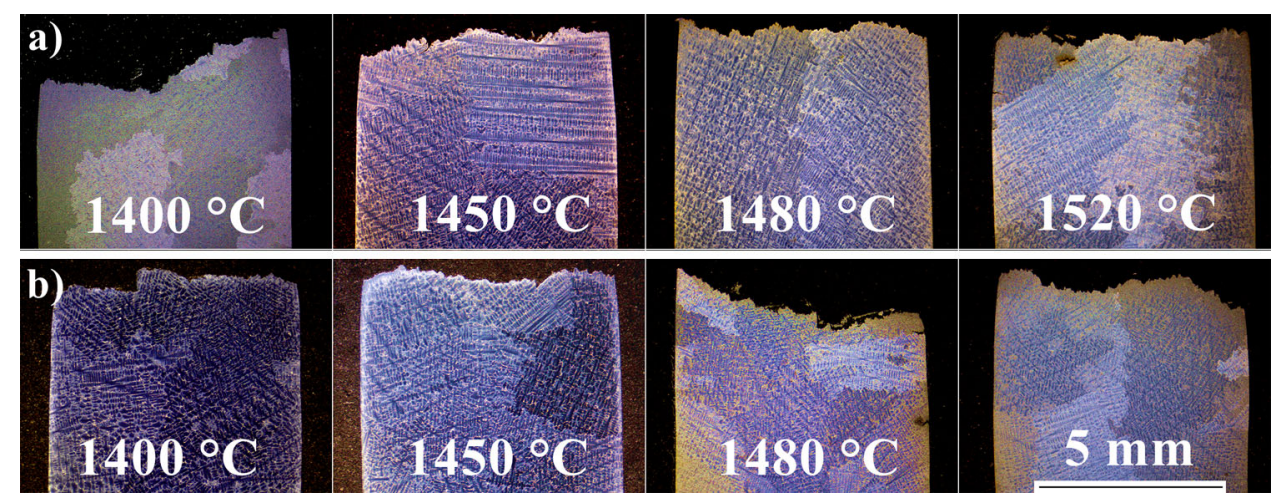

Fig. 5 Cross sections after tensile testing: (a) unmodified castings; (b) modified castings 

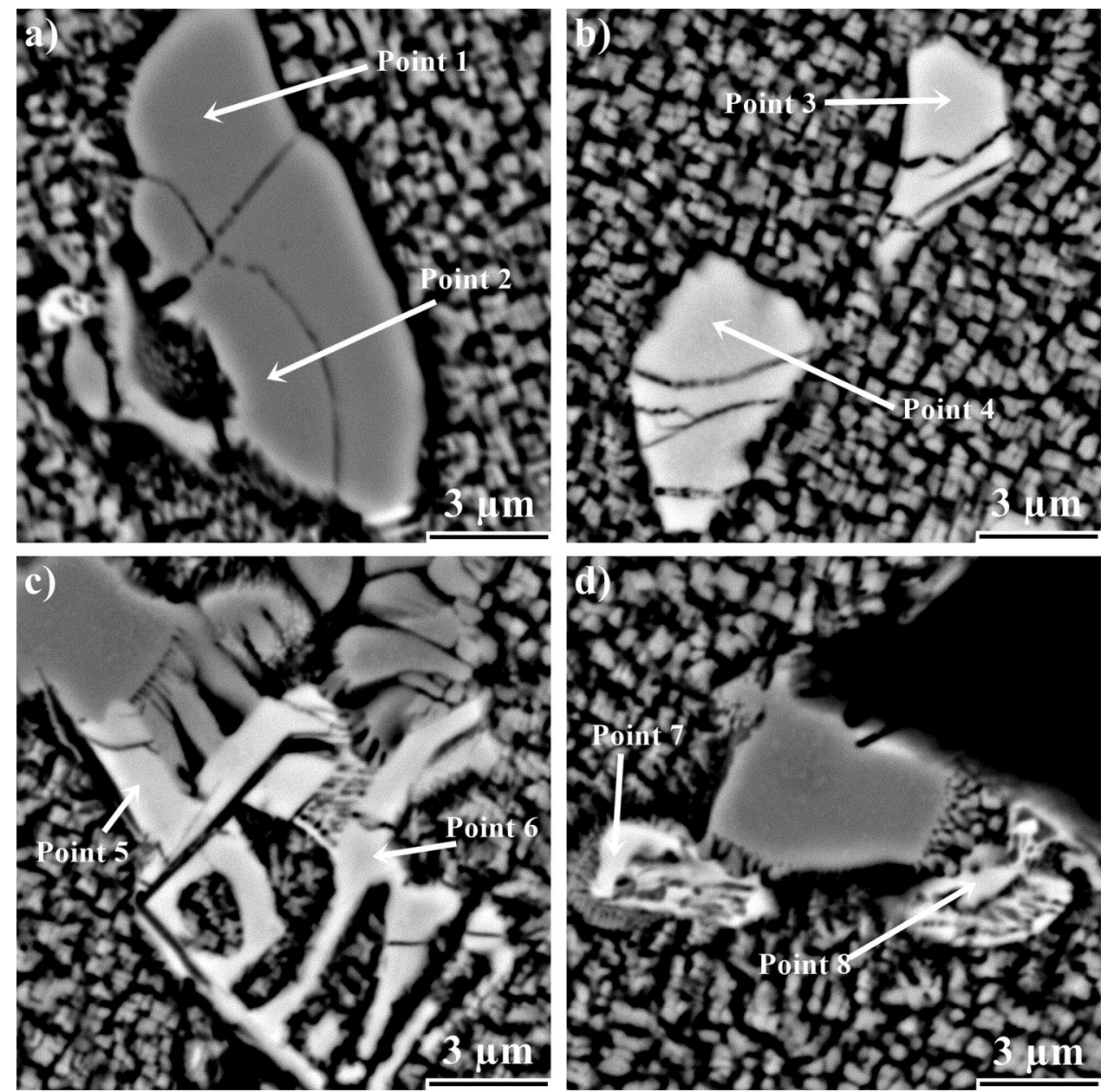

Fig. 6 Microcracks of precipitates: (a) eutectic $\gamma^{\prime}$; (b) MC-type carbides; (c) $\mathrm{M}_{3} \mathrm{~B}_{2}$ boride; (d) intermetallic compound $\mathrm{Ni}_{7} \mathrm{Zr}_{2}$

Table 3 Concentration of alloying elements in selected points (at.\%)

\begin{tabular}{lrrrrrrr}
\hline Point/element & Al & Cr & Nb & Ti & Mo & $\mathbf{Z r}$ & Ni \\
\hline 1 & 16.1 & 4.3 & 3.3 & 2.4 & 1.3 & 1.0 & 71.6 \\
2 & 15.9 & 4.2 & 3.4 & 2.3 & 1.3 & 1.0 & 71.9 \\
3 & 0.9 & 1.5 & 59.5 & 11.8 & 13.9 & 7.4 & 5.0 \\
4 & 3.1 & 1.6 & 56.1 & 9.4 & 9.9 & 10.8 & 9.1 \\
5 & 1.7 & 26.9 & 8.1 & 0.8 & 50.0 & 3.2 & 9.3 \\
6 & 1.8 & 30.6 & 8.5 & 0.9 & 44.7 & 2.3 & 11.2 \\
7 & 6.0 & 2.6 & 3.5 & 0.8 & 1.2 & 17.4 & 68.5 \\
8 & 5.1 & 2.5 & 3.7 & 0.7 & 0.8 & 17.4 & 69.8 \\
\hline
\end{tabular}

dislocation creep drops rapidly, while creep rate through a diffusion mechanism decreases. The microstructure of crept Inconel $713 \mathrm{C}$ is shown in Fig. 8. Intergranular cracks with numerous secondary cracks and voids were observed. The main microstructural change in the dendrite cores was directional growth (rafting) of $\gamma^{\prime}$ precipitates (Fig. 9). The rafting process of $\gamma^{\prime}$ phase in Ni-based superalloys is induced by several factors, namely the value and direction of the external stress, the value of misfit coefficient and the elastic constant of $\gamma^{\prime}$ and $\gamma$ phases (Ref 29).
The morphology change in $\gamma^{\prime}$ phase was $N$-type rafting, in which the lamellae of $\gamma^{\prime}$ phase were perpendicular to the applied tensile stress direction. Lattice misfit is defined as $\delta=2\left(a_{\gamma^{\prime}}-a_{\gamma}\right) /\left(a_{\gamma^{\prime}}+a_{\gamma}\right)$, where $a_{\gamma^{\prime}}$ and $a_{\gamma}$ are lattice constants (Ref 31). When lattice misfit is negative, it can be concluded that the rafting is a sequential process (Ref 32, 33). At the beginning, plastic deformation of the matrix takes place, which leads to a loss of coherency at the $\gamma / \gamma^{\prime}$ interface and decrease in the misfit stress. Tensile stresses act in the $\gamma^{\prime}$ precipitates parallel to the matrix channels. Compressive stresses in the surfaces of matrix channels balance these forces, and moreover, they are much higher than the tensile stress components perpendicular to the channels. The combination of internal stresses yields a specific value for the hydrostatic stress, which is well known to directly affect the chemical potential of atoms (Ref 30). If the superalloy is not loaded $(\sigma=0)$, the tendency to reduce the overall $\gamma / \gamma^{\prime}$ interface energy leads to non-directional coarsening of cubic precipitates (Fig. 10a). In this case, the chemical potentials of the $\gamma^{\prime}$ phase at points 1 and 2 are equal. When the external stress is applied, the stress components at positions 1 and 2 are not the same (Fig. 10b). The local stresses inside material are modified in the direction of the applied external stress. The internal stresses change to perpendicular to the external stress axis because of the difference in values of Poisson's ratio of the matrix and the 

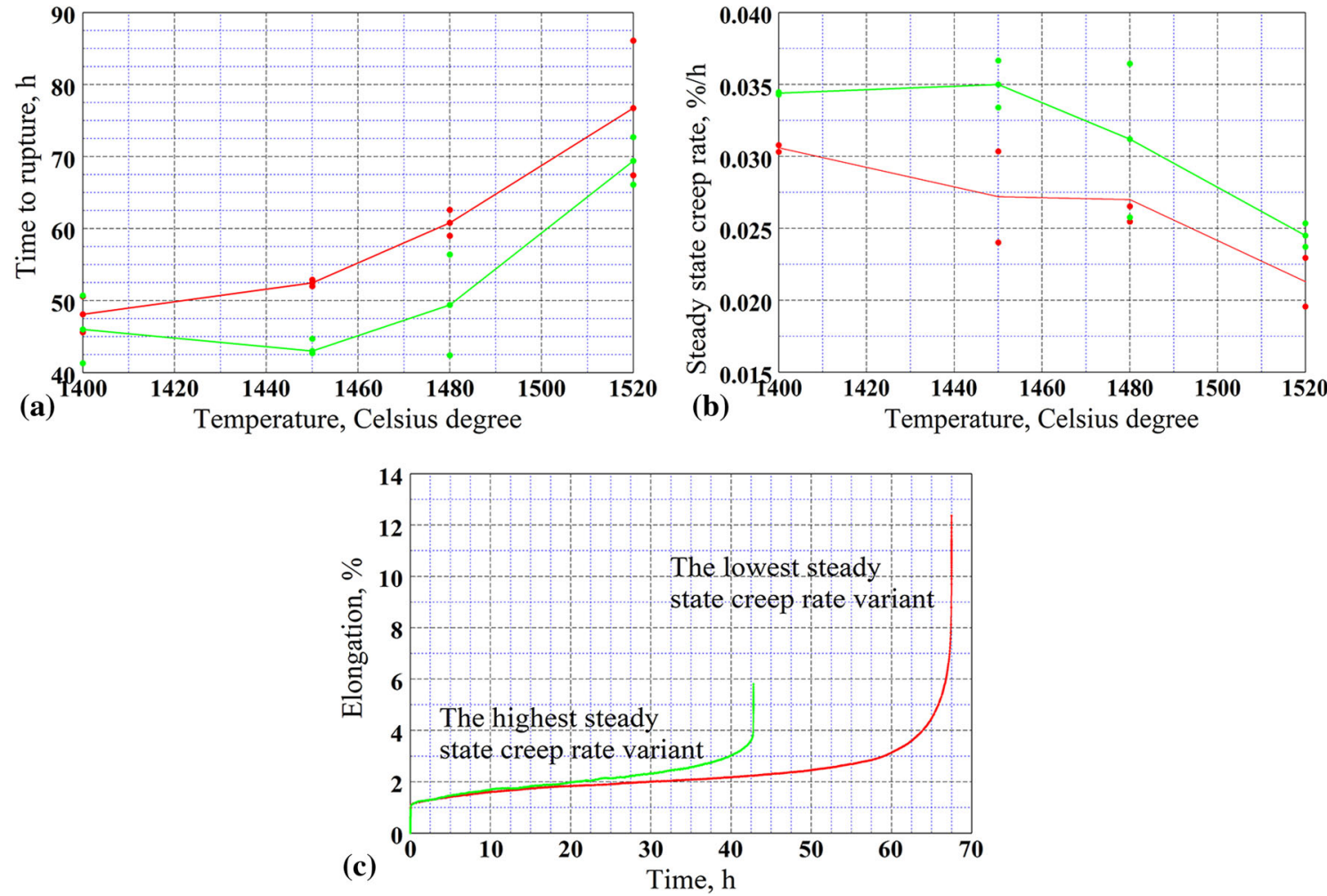

Fig. 7 Results of creep tests: (a) time to rupture; (b) steady-state creep rate: (c) comparison of creep curves for variants characterized by the highest and the lowest steady-state creep rate

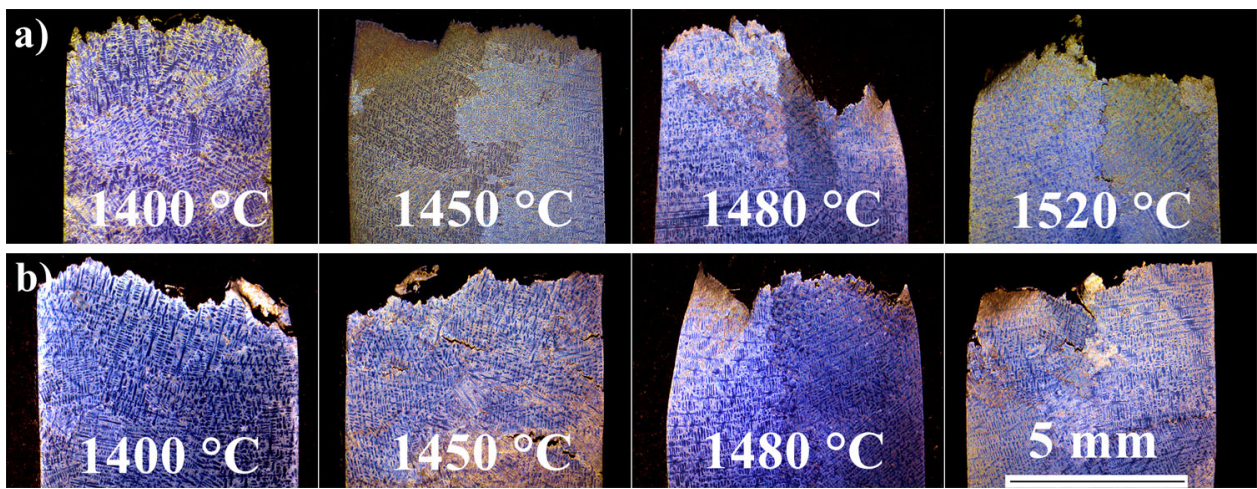

Fig. 8 Microstructure of cross sections after creep: (a) unmodified castings; (b) modified castings

precipitates. The effective stress in the perpendicular channels of the matrix is greater than in the parallel channels, which favors diffusion processes and dislocation movement in the perpendicular channels. The result is rafting of $\gamma^{\prime}$ perpendicularly to the external tensile direction.

Morphology of constituents and location of EDS lines are shown in Fig. 11 and 12. Microstructural observations in interdendritic spaces revealed much more complex changes, and so selected regions were subjected to EDS analysis. In Fig. 12(a), the enrichment in $\mathrm{Nb}$ and $\mathrm{Ti}$ was observed, which suggests that it was a primary $\mathrm{Nb}$-rich carbide surrounded by the coarse-grained $\gamma^{\prime} . \mathrm{M}_{3} \mathrm{~B}_{2}$ boride enriched in $\mathrm{Mo}$ and $\mathrm{Cr}$ (Fig. 12b) did not transform during creep. Intermetallic compound $\mathrm{Ni}_{7} \mathrm{Zr}_{2}$ (Fig. 12c) was also stable during exposure to $982{ }^{\circ} \mathrm{C}$. Inside interdendritic $\gamma^{\prime}$ phase, near the $\mathrm{MC}$ type carbides, precipitates strongly enriched in $\mathrm{Cr}$ were observed (Fig. 12d). These precipitates were not present in the as-cast state. In Ni-based superalloys, MC-type carbides can decompose during exposure to high temperature by one of the transformations: $\mathrm{MC}+\gamma \rightarrow \mathrm{M}_{23} \mathrm{C}_{6}+\gamma^{\prime}, \mathrm{MC}+$ $\gamma \rightarrow \mathrm{M}_{6} \mathrm{C}+\gamma^{\prime}$ and/or $\mathrm{MC}+\gamma \rightarrow \mathrm{M}_{23} \mathrm{C}_{6}+\eta$. Despite intensive observation, $\mathrm{M}_{6} \mathrm{C}$ carbide and intermetallic $\eta$ phase 
were not observed in IN713C, which was earlier reported by (Ref 6).

\section{Conclusions}

Melt-pouring temperature and the composition of the primary coat in the shell mold influenced grain size of IN713C castings and consequently their mechanical properties both at ambient temperature and $982{ }^{\circ} \mathrm{C}$. This work combines

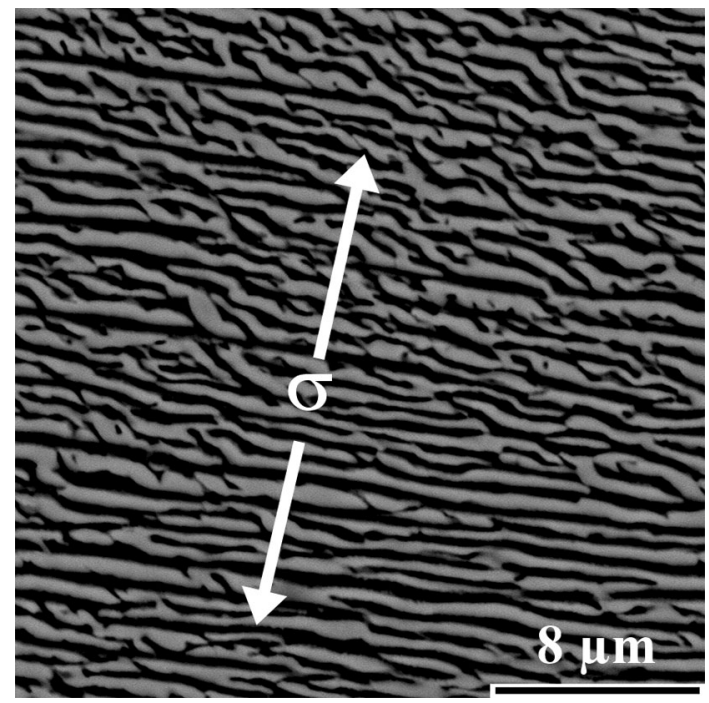

Fig. 9 Morphology of rafted $\gamma^{\prime}$

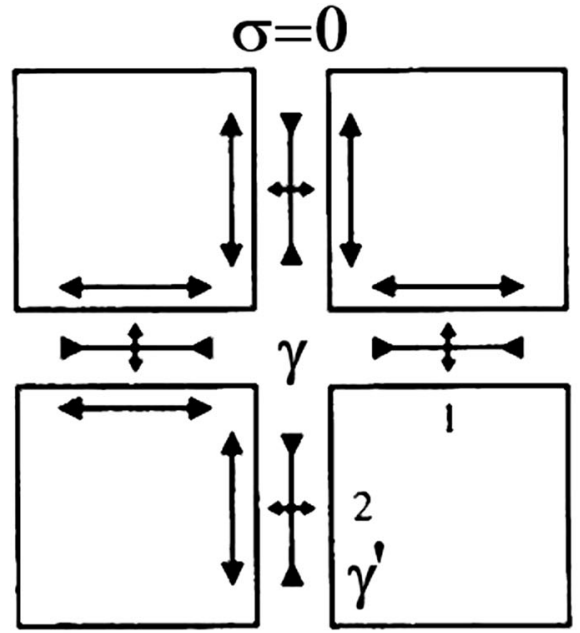

(a) two variants of the primary coat, without and with the addition of $5 \% \mathrm{CoAl}_{2} \mathrm{O}_{4}$ inoculant, and also four pouring temperatures from 1400 to $1520{ }^{\circ} \mathrm{C}$. The main conclusions of the research are:

(a) The compound $\mathrm{CoAl}_{2} \mathrm{O}_{4}$ is suitable for surface modification of IN713C castings. The highest grain refinement was obtained in castings poured between 1450 and $1520{ }^{\circ} \mathrm{C}$,

(b) The mean yield strength in unmodified samples decreased with the increase in melt-pouring temperature, while elongation $A_{4}$ had the opposite relation. The highest mean yield strength $(815 \mathrm{MPa})$ was obtained in modified samples poured from $1520^{\circ} \mathrm{C}$,

(c) The time to rupture increased with the increase in meltpouring temperature both for unmodified and modified castings. The difference between the lowest and the highest time to rupture $(72.8 \mathrm{~h})$ for unmodified castings was $28.7 \mathrm{~h}$. Modified castings were characterized by a similar difference between the lowest and highest time to rupture $(69.4 \mathrm{~h})$ at $1520{ }^{\circ} \mathrm{C}$, equal to $26.4 \mathrm{~h}$,

(d) The changes in microstructure during tensile testing included microcracking of large strengthening phases,

(e) During creep, $N$-type rafting of $\gamma^{\prime}$ and transformation of $\mathrm{MC}$ carbides to $\mathrm{M}_{23} \mathrm{C}_{6}$ carbides in interdendritic spaces $\left(\mathrm{MC}+\gamma \rightarrow \mathrm{M}_{23} \mathrm{C}_{6}+\gamma^{\prime}\right)$ were observed,

(f) The best combination of mechanical properties, for application in intermediate service temperature (LPT section) in jet engines, was for modified IN713C with $1520{ }^{\circ} \mathrm{C}$ pouring temperature. The temperature is below the creep range, where stresses originating from centrifugal loads are high. In this case, the best combination of tensile strength and creep resistance is required.

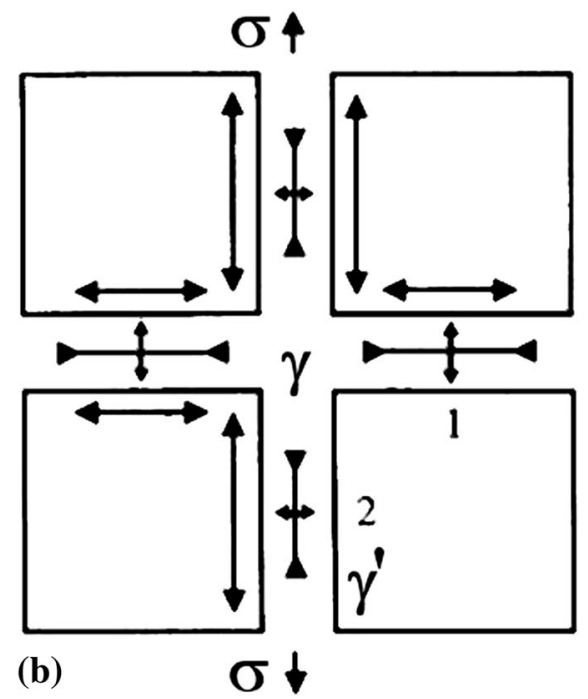

Fig. 10 Representation of internal stress components in the $\gamma$ and $\gamma^{\prime}$ phases: (a) $\sigma=0$; (b) $\sigma>0$ (Ref 30) 

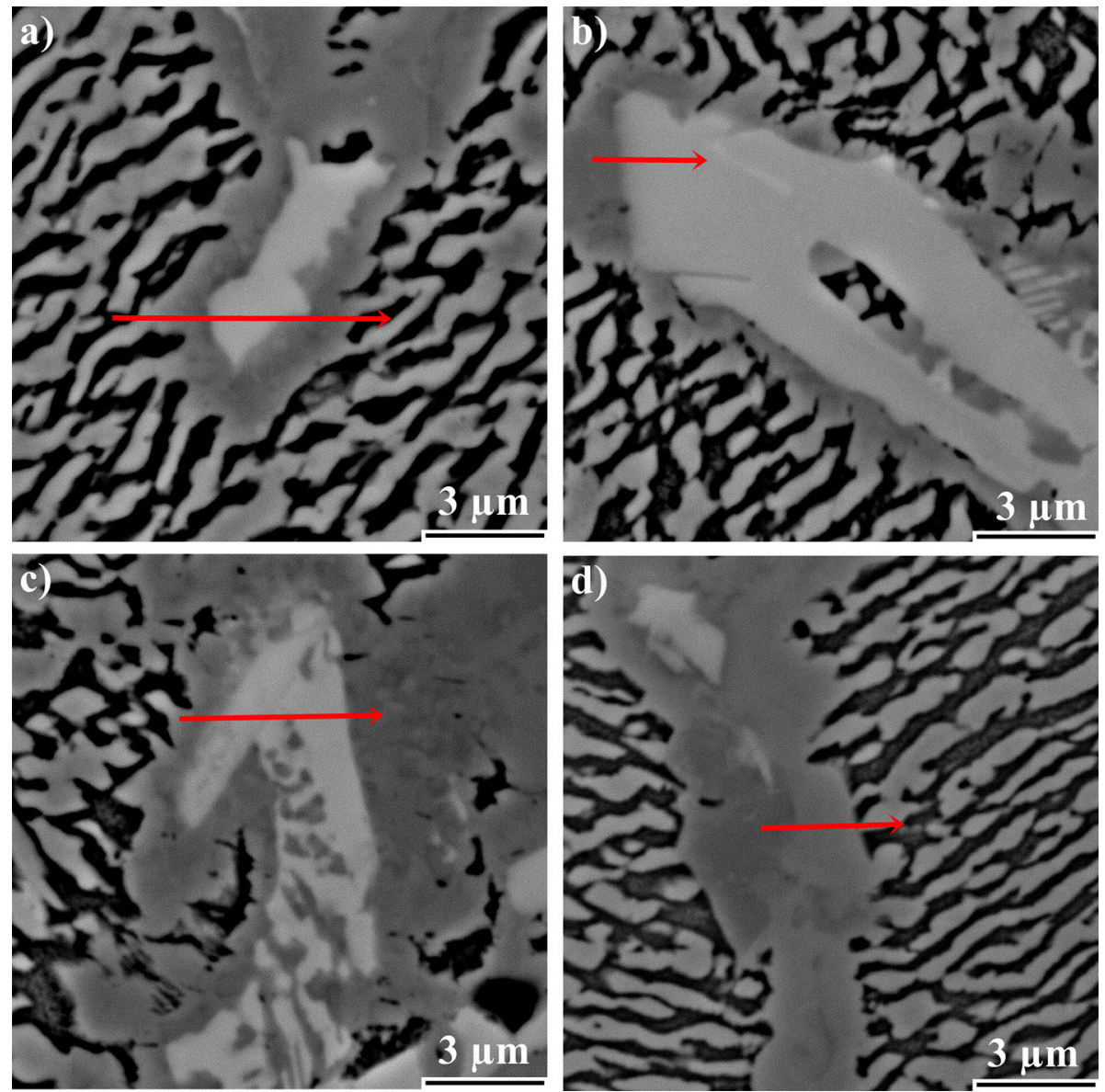

Fig. 11 Morphology of phases after creep and location of EDS lines: (a) MC-type carbide; (b) $\mathrm{M}_{3} \mathrm{~B}_{2}$ boride; (c) intermetallic compound $\mathrm{Ni}_{7} \mathrm{Zr}_{2} ;$ (d) $\mathrm{M}_{23} \mathrm{C}_{6}$ Cr-rich carbides
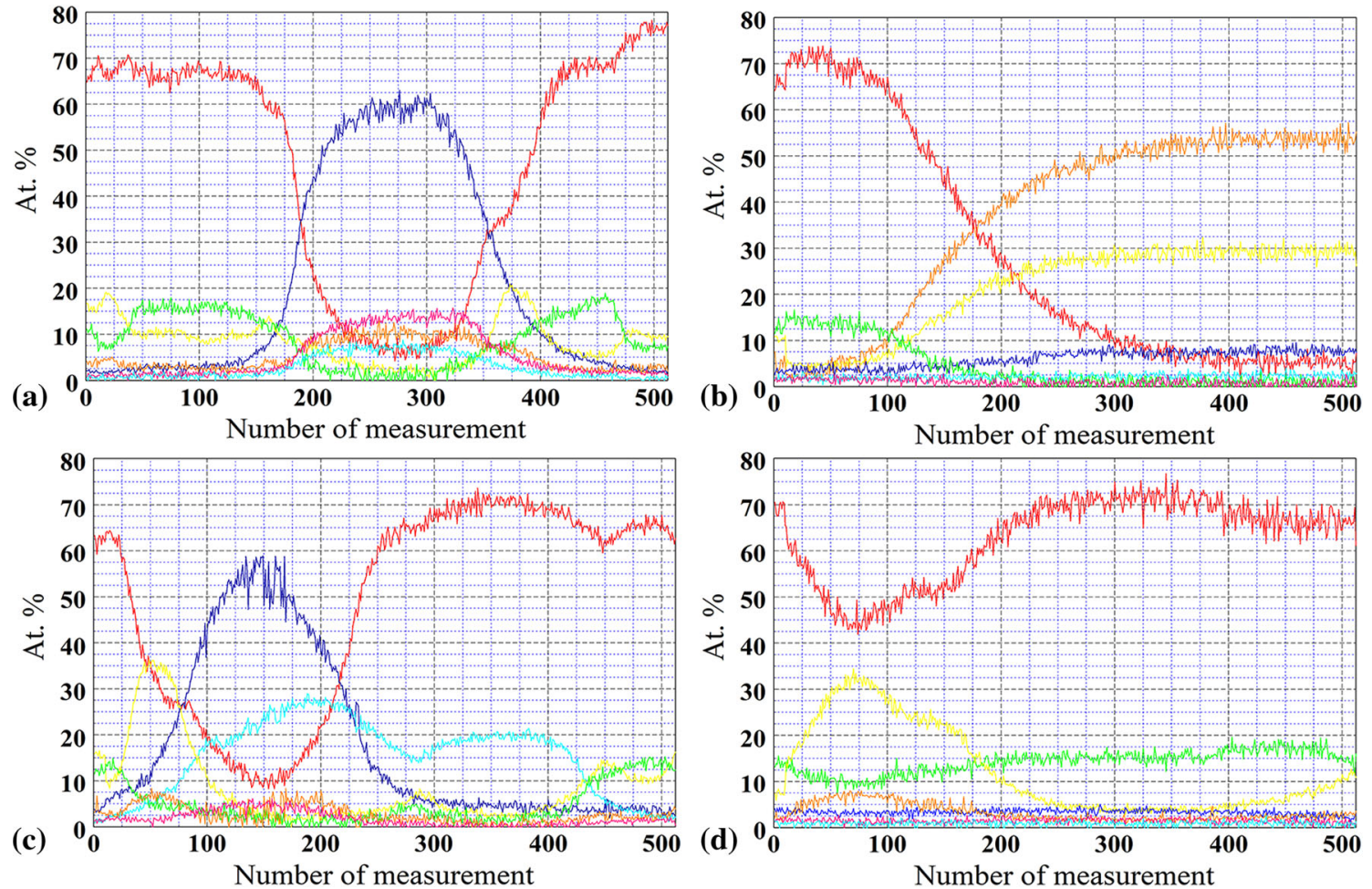

Fig. 12 Distribution of alloying elements (at.\%): (a) $\mathrm{MC}$ carbide and $\gamma^{\prime}$; (b) $\mathrm{M}_{3} \mathrm{~B}_{2}$ boride and $\gamma^{\prime} ;$ (c) $\mathrm{Ni}_{7} \mathrm{Zr}_{2}$ and $\mathrm{MC}$ carbide; (d) $\mathrm{M}_{23} \mathrm{C}_{6} \mathrm{Cr}$-rich carbides and $\gamma^{\prime}$. Colors: $\mathrm{Ni}$ - red, $\mathrm{Mo}$ - orange, $\mathrm{Cr}$ - yellow, $\mathrm{Al}$ - green, $\mathrm{Nb}$ - blue, $\mathrm{Zr}$ - turquoise, $\mathrm{Ti}$ - pink (Color figure online) 


\section{Acknowledgments}

The authors gratefully acknowledge the funding by National Centre for Research and Development Poland under Grant LIDER/ 227/L-6/14/NCBR/2015 "New technology for investment casting manufacturing critical engine components with a new generation ceramic materials."

\section{Open Access}

This article is distributed under the terms of the Creative Commons Attribution 4.0 International License (http://creativecommons.org/ licenses/by/4.0/), which permits unrestricted use, distribution, and reproduction in any medium, provided you give appropriate credit to the original author(s) and the source, provide a link to the Creative Commons license, and indicate if changes were made.

\section{References}

1. R. Reed, The Superalloys: Fundamentals and Applications, Cambridge University Press, Cambridge, 2006

2. H. Long et al., Microstructural and Compositional Design of Ni-Based Single Crystalline Superalloys-A Review, J. Alloys Compd., 2018, 743, p 203-220. https://doi.org/10.1016/j.jallcom.2018.01.224

3. Ł. Rakoczy and R. Cygan, Analysis of Temperature Distribution in Shell Mould During Thin-Wall Superalloy Casting and its Effect on the Resultant Microstructure, Arch. Civ. Mech. Eng., 2018, 18, p 14411450. https://doi.org/10.1016/j.acme.2018.05.008

4. F. Zupanic et al., Structure of Continuously Cast Ni-Based Superalloy Inconel 713, J. Alloys Compd., 2001, 329, p 290-297. https://doi.org/ 10.1016/S0925-8388(01)01676-0

5. M. Azadi et al., Effects of Solutioning and Ageing Treatments on Properties of Inconel-713C Nickel-Based Superalloy Under Creep Loading, Mater. Sci. Eng. A, 2018, 711, p 195-204

6. H. Matysiak et al., The Microstructure Degradation of the IN 713C Nickel-Based Superalloy After the Stress Rupture Tests, J. Mater. Eng. Perform., 2014, 23(9), p 3305-3313. https://doi.org/10.1007/s11665014-1123-4

7. A. Szczotok and H. Matysiak, Influence of Constituents of Shell Mold on the Morphology and Chemical Composition of Carbides Occurring in IN 713C Superalloy Castings, J. Mater. Eng. Perform., 2014, 23(8), p 2748-2759. https://doi.org/10.1007/s11665-014-1035-3

8. L. Thébaud et al., Is There an Optimal Grain Size for Creep Resistance in Ni-Based Disk Superalloys?, Mater. Sci. Eng. A, 2018, 716, p 274 283. https://doi.org/10.1016/j.msea.2017.12.104

9. J. Salvant Canto et al., A Study of Low Cycle Fatigue Life and Its Correlation with Microstructural Parameters in IN713C Nickel Based Superalloy, Mater. Sci. Eng. A, 2018, 718, p 19-32. https://doi.org/10. 1016/j.msea.2018.01.083

10. K. Young-Wang et al., A Numerical Model to Predict Mechanical Properties of Ni-Base Disk Superalloys, Int. J. Plast., 2018, 110, p 123-144. https://doi.org/10.1016/j.ijplas.2018.06.011

11. H. Matysiak et al., The Influence of the Melt-Pouring Temperature and Inoculant Content on the Macro and Microstructure of the IN713C NiBased Superalloy, J. Miner., 2016, 68(1), p 185-197. https://doi.org/10. 1007/s11837-015-1672-5

12. C.H. Konrad et al., Determination of Heat Transfer Coefficient and Ceramic Mold Material Parameters for alloy IN738LC Investment Castings, J. Mater. Proc. Technol., 2011, 211, p 181-186. https://doi. org/10.1016/j.jmatprotec.2010.08.031
13. W. Jin et al., Grain Refinement of Superalloy IN100 Under the Action of Rotary Magnetic Fields and Inoculants, Mat. Let., 2008, 62, p 15851588. https://doi.org/10.1016/j.matlet.2007.09.028

14. F. Wang et al., Preparation of Inoculants Used in Superalloy and Analysis of the Atomic Matching Models, J. Mater. Sci. Technol., 2013, 29(4), p 387-392. https://doi.org/10.1016/j.jmst.2013.02.007

15. L. Liu et al., Grain Refinement of Superalloy K4169 by Addition of Refiners: Cast Structure and Refinement Mechanisms, Mater. Sci. Eng. A, 2005, 394, p 1-8. https://doi.org/10.1016/j.msea.2004.10.005

16. B. Du et al., Effects of Grain Refinement on the Microstructure and Tensile Behavior of K417G Superalloy, Mater. Sci. Eng. A, 2015, 623, p 59-67. https://doi.org/10.1016/j.msea.2014.11.041

17. C.N. Wei et al., A Study of IN-713LC Superalloy Grain Refinement Effects on Microstructure and Tensile Properties, Mater. Chem. Phys., 2003, 80, p 89-93

18. B. Du et al., Effects of grain size on the high-cycle fatigue behavior of IN792 superalloy, Mater. Des., 2015, 65, p 57-64. https://doi.org/10. 1016/j.matdes.2014.08.059

19. ASTM E8M-13a Standard-Standard Test Methods for Tension Testing of Metallic Materials

20. ASTM E139-11-Standard Test Methods for Conducting Creep, Creep-Rupture, and Stress-Rupture Tests of Metallic Materials

21. R.W.G. Wyckoff, Crystal Structures: Cubic Closest Packed, Interscience, New York, 1963

22. S. Ackerbauer et al., The Constitution of the Ternary System Fe-Ni-Si, Intermet, 2009, 17(6), p 414-420. https://doi.org/10.1016/j.intermet. 2008.11.016

23. AMS 5391 standard-Nickel Alloy, Corrosion and Heat Resistant, Investment Castings, $73 \mathrm{Ni} 13 \mathrm{Cr} 4.5 \mathrm{Mo} 2.3 \mathrm{Cb} 0.75 \mathrm{Ti} 6.0 \mathrm{Al} 0.010 \mathrm{~B}$ $0.10 Z$ r Vacuum Cast, As-Cast

24. R. Reed and C.M.F. Rae, Physical Metallurgy of the Nickel-Based Superalloys, Physical Metallurgy (Fifth Edition), 2014, p 2215-2290. h ttps://doi.org/10.1016/B978-0-444-53770-6.00022-8

25. A. Epishin and T. Link, Mechanisms of High Temperature Creep of Nickel-Base Superalloys Under Low Applied Stress, Phil. Mag., 2004, 84(19), p 1979-2000. https://doi.org/10.1080/1478643041000 1663240

26. X.Z. Qin et al., Decomposition of Primary MC Carbide and its Effects on the Fracture Behaviors of a Cast Ni-Base Superalloy, Mater. Sci. Eng. A, 2008, 485(1-2), p 74-79. https://doi.org/10.1016/j.msea.2007. 07.055

27. J. Yang et al., Effects of Different C Contents on the Microstructure, Tensile Properties and Stress-Rupture Properties of IN792 Alloy, Mater. Sci. Eng. A, 2011, 528(3), p 1534-1539. https://doi.org/10.1016/ j.msea.2010.11.003

28. F. Nabarro, The Physics of Creep, Taylor and Francis, London, 1995

29. P. Nörtershäuser et al., The Effect of Cast Microstructure and Crystallography on Rafting, Dislocation Plasticity and Creep Anisotropy of Single Crystal Ni-Base Superalloys, Mater. Sci. Eng. A, 2015, 626, p 305-312. https://doi.org/10.1016/j.msea.2014.12.030

30. M. Kamaraj et al., On the Influence of Stress State on Rafting in the Single Crystal Superalloy CMSX-6 Under Conditions of High Temperature and Low Stress Creep, A. Metall., 1998, 38(4), p 589-594

31. A. Royer et al., In Situ Determination of $\gamma^{\prime}$ Phase Volume Fraction and of Relations Between Lattice Parameters and Precipitate Morphology in Ni-Based Single Crystal Superalloy, Acta Mater., 1998, 46(15), p 5357-5368. https://doi.org/10.1016/S1359-6454(98)00206-7

32. W. Huang et al., Experimental Investigation and Modelling of Microstructure Degradation in a DS Ni-Based Superalloy Using a Quantitative Cross Correlation Analysis Method, J. Alloys Compd., 2018, 762, p 488-499. https://doi.org/10.1016/j.jallcom.2018.05.131

33. V. Caccuri et al., $\gamma^{\prime}$-Rafting Mechanisms Under Complex Mechanical Stress State in Ni-Based Single Crystalline Superalloy, Mater. Des., 2017, 131, p 487-497. https://doi.org/10.1016/j.matdes.2017. 06.018 